\title{
Assessment of human papillomavirus and Epstein-Barr virus in lung adenocarcinoma
}

\author{
WAN-TECK LIM ${ }^{1}$, KHOON LEONG CHUAH ${ }^{2}$, SWAN SWAN LEONG ${ }^{1}$, \\ ENG HUAT TAN ${ }^{1}$ and CHEE KEONG TOH ${ }^{1}$ \\ ${ }^{1}$ National Cancer Center Singapore, 11 Hospital Drive, Singapore 169610 \\ ${ }^{2}$ Singapore General Hospital, Outram Road, Singapore 169608, Republic of Singapore
}

Received July 11, 2008; Accepted September 30, 2008

DOI: $10.3892 /$ or_00000310

\begin{abstract}
The association of human papillomavirus (HPV) and Epstein-Barr virus (EBV) infection with non-small cell lung cancer is controversial. HPV and EBV prevalence in a uniform population of lung adenocarcinoma was investigated, hypothesizing that there would be differences seen between smokers and non-smokers and between sexes. Patients involved in this study were selected from a single institution database of lung cancer. In total 497 patients with adenocarcinoma were identified and 110 patients had sufficient tissue for analysis with an in situ hybridization method that probed for high-risk and low-risk HPV and EBV. There were 65 males and 45 females, 78 patients with stage I-IIIA disease and 32 patients with stage IIIB-IV disease. There were similar number of smokers and non-smokers. Across all stages HPV and EBV staining was absent from all tissues examined. It is unlikely that HPV or EBV is an important etiological agent in adenocarcinoma of the lung, even among the neversmokers.
\end{abstract}

\section{Introduction}

Cigarette smoke is strongly associated with the development of lung cancer (1). While the epidemic of smoking has reduced through public health awareness programs and education, the incidence of lung cancer remains unabated. There has been a demographic change in the global pandemic with a global realignment of histological subtypes. Adenocarcinoma incidence is rising globally among both smokers and nonsmokers. Up to $30 \%$ of all diagnosed non-small cell lung cancer (NSCLC) among various Asian countries, including Singapore, do not have a history of exposure to cigarette smoking. These patients tend to be predominantly female and have adenocarcinoma (2). This has given rise to different

Correspondence to: Dr Wan-Teck Lim, Department of Medical Oncology, National Cancer Centre Singapore, 11 Hospital Drive, Singapore 169610

E-mail: dmolwt@nccs.com.sg

Key words: lung adenocarcinoma, human papillomavirus, EpsteinBarr virus postulates as to the possible etiologies of NSCLC in this distinct of patients, ranging from exposure to cooking oil fumes $(3,4)$, as well as diet and cancer susceptibility genotypes among Asians (5-7). Human papillomavirus (HPV) and Epstein-Barr virus (EBV) have been variously described to be associated and causative with several cancers. HPV is likely to be causal in cervical carcinoma and head and neck squamous cell carcinoma (HNSCC), and EBV in nasopharyngeal carcinoma. There have been various reports of association between HPV and EBV with lung cancer but results have not been conclusive (8). Leveraging on the excess of non-tobacco related lung cancer in our patients we investigated HPV and EBV prevalence in a uniform population of adenocarcinoma of the lung, hypothesizing that there would be differences seen between smokers and nonsmokers and between sexes.

\section{Patients and methods}

Patients. Patients involved in this study were selected from a database of NSCLC patients, diagnosed in a single institution (SGH) from 1999 to 2002. The study had the approval of the Institutional Review Board of National Cancer Centre Singapore. The main selection criterion was a diagnosis of adenocarcinoma. Four hundred and ninety-seven patients were identified and among them, 110 patients had sufficient tissue blocks available for our analysis using in situ hybridization method for HPV and EBV. The tissue samples were reviewed and confirmed by the collaborating pathologist (KLC). Fivemicrometer slices from paraffin embedded tissue blocks were used for the analysis.

HPV and EBV in situ hybridization method. This in situ hybridization procedure was done in the Department of Pathology, Singapore General Hospital. Sections from paraffin-embedded tissues were deparaffinised and subjected to a series of steps as described by Brousset et al (9). The probes for the various infective agents described below were used according to the manufacturer's recommendations.

For human papillomavirus (HPV) study, peptidic nucleic acid (PNA) probes from Ventana (Ventana Medical Systems, Tucson, AZ, USA) were used. HPV II family 6 probe (catalog no. 800-2220, Ventana) containing a cocktail detecting the low-risk genotypes 6 and 11 was used while HPV II family 
Table I. Patient characteristics $(n=110)$.

\begin{tabular}{llr}
\hline & & $\mathrm{n}(\%)$ \\
\hline Age & Median (years) & 64 \\
Race & Chinese & $110(100)$ \\
Sex & Male & $65(59)$ \\
& Female & $45(41)$ \\
Smoker status & Never-smoker & $54(49)$ \\
& Smoker & $56(51)$ \\
Stage & I-IIIA & $78(71)$ \\
& IIIB-IV & $32(29)$ \\
\hline
\end{tabular}

16 probe (catalog no. 800-2219) containing a cocktail detecting high-risk genotypes $16,18,31,33,35,45,51,52,56,58$ and 66 was used. For Epstein-Barr virus (EBV), PNA probes from Ventana (Epstein-Barr Early RNA probe, catalog no. 780-2842) were used.

Appropriate positive and negative control tissues as well as positive and negative reagent controls were used during the procedure. A positive result was read when there was significant nuclear staining of the cells tested.

\section{Results}

One hundred and ten tissue samples were retrieved from the Department of Pathology. Patient demographics are illustrated
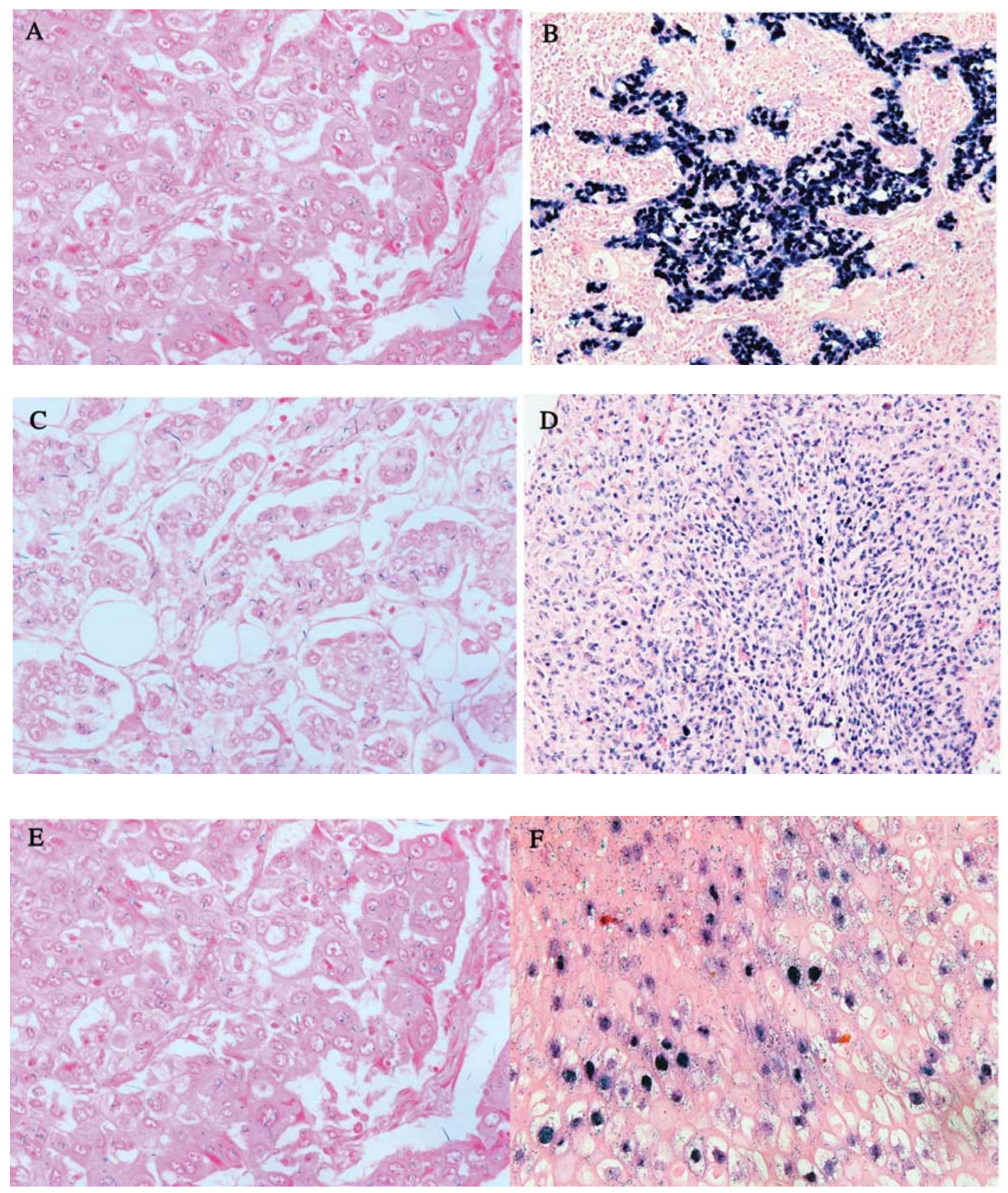

Figure 1. (A) Absence of EBV by ISH in lung adenocarcinoma (x400). (B) Paired positive control for EBER probe (x200). (C) Absence of high-risk HPV by ISH in lung adenocarcinoma (x400). (D) Paired positive control for HPV family 16 probe (x200). (E) Absence of low-risk HPV by ISH in lung adenocarcinoma (x400). (F) Paired positive control for HPV family 6 probe (x400). 
Table II. Selected studies of HPV in non-small cell lung cancer.

\begin{tabular}{|c|c|c|c|c|c|}
\hline Author/Refs. & Country & Methods & $\mathrm{n}$ & $\begin{array}{c}\text { Histology } \\
\text { (Adenoca./ } \\
\text { non-adenoca.) }\end{array}$ & HPV serotypes \\
\hline Syrjanen (8) & Finland & ISH & 131 & $0 / 131$ & $6(1.5 \%), 16(5.3 \%)$ \\
\hline Kaya, et al (19) & Turkey & ISH & 26 & $0 / 26$ & $16 / 18(7.7 \%), 6 / 11(3.8 \%)$ \\
\hline Gorgoulis, et al (20) & Greece & PCR and ISH & 68 & $32 / 36$ & $16 / 18(0 \%)$ \\
\hline Szabo, et al (22) & Japan & PCR & 47 & $0 / 47$ & $6,11,16,18,31,33,52 \mathrm{~b}$, and 58 (all $0 \%)$ \\
\hline Aguayo, et al (23) & Chile & $\begin{array}{l}\text { PCR and Southern } \\
\text { blotting }\end{array}$ & 69 & Not stated & $16(29 \%)$ \\
\hline Noutsou, et al (24) & Greece & PCR & 99 & $41 / 58$ & $16(4 \%), 18(8 \%), 11(3 \%), 33(2 \%)$ \\
\hline Giulani, et al (25) & Italy & Blot hybridisation & 78 & $27 / 51$ & $\begin{array}{l}16(3.8 \%), 31(1.3 \%), 6 / 53(2.6 \%), \\
16 / 18(1.3 \%)\end{array}$ \\
\hline Kinoshita, et al (26) & Japan & PCR & 36 & $22 / 24$ & $18(8 \%)$ \\
\hline Iwamasa, et al (28) & Japan & PCR and ISH & 44 & $0 / 44$ & $16 / 18(57 \%)$ \\
\hline Cheng, et al (29) & Taiwan & $\begin{array}{l}\text { Nested PCR } \\
\text { and ISH }\end{array}$ & 141 & $83 / 58$ & $16 / 18(54.6 \%)$ \\
\hline Fei, et al (30) & China & Nested PCR/ISH & 73 & $33 / 40$ & $16(26 \%), 18(23.3 \%), 16 / 18(27.7 \%)$ \\
\hline Park, et al (31) & Korea & PCR & 112 & $53 / 59$ & $16(10.7 \%), 18(9.8 \%), 33(33 \%)$ \\
\hline Jain, et al (32) & India & PCR & 40 & $9 / 31$ & $18(5 \%)$ \\
\hline Coissard, et al (34) & France & Line blot assay & 218 & $80 / 138$ & $16(1.8 \%)$ \\
\hline Clavel, et al (35) & France & Hybrid capture II & 185 & $60 / 125$ & High-risk $(2.7 \%)$ \\
\hline
\end{tabular}

in Table I. There were similar number of smokers and nonsmokers (56/54). There were 65 males and 45 females, 78 patients with stage I-IIIA disease and 32 patients with stage IIIB-IV disease. HPV and EBV were uniformly absent from this large population of lung adenocarcinoma screened (Fig. 1).

\section{Discussion}

The current study failed to demonstrate the presence of HPV or EBV DNA by an in situ hybridization method in any of the tumors that were screened. We acknowledge that in situ hybridization methods have only moderate sensitivity for detection of HPV, and there could be a false-negative rate (10). However, there remains no uniform technology for detection of HPV. In situ hybridization methods that combine polymerase chain reaction (PCR) methods while more sensitive are also prone to false-negative rates from failed amplification when fragmented DNA extracted from paraffin-embedded tissue is used, and false-positive rates from amplification of other DNA (11), and are not routinely available in service pathology labs. One significant advantage of this in situ hybridization method is that it allows for demonstration of the viral genome within tumor, and it can be routinely used to evaluate paraffin-embedded tissues. This is especially important in lung cancer where tissue samples are often small and limited. Although we were able to retrieve only about $25 \%$ of the intended population of adenocarcinoma, the 110 patient samples analyzed is not small and may be considered one of the larger studies. In addition, our analysis includes a high proportion of never-smokers, which is important to answer the association of these viruses with lung cancer among this distinct group of patients.

There is no strong explanation for HPV reaching and infecting lung tissue. HPV has long been thought not to have a viraemic phase in humans, although more recent data suggests that it my not be so $(12,13)$. In lung cancer, Chiou et al raised the possibility of viraemic spread when they described a $70 \%$ concordance rate between HPV DNA in peripheral blood and paired lung cancer tissue (14). Even if viraemic spread were possible the low prevalence of HPV in the general population would imply a low rate of HPV infection in lung if any. HPV prevalence among women in Singapore is estimated at 5\% (15), for South East Asia is low (16), and for women in Asia with normal cervical histology/ cytology this rate stands at $14.4 \%$ (17). More conventionally, however, HPV spreads by local contact or seeding from nearby tissue. The development of lung squamous cell carcinomas by seeding from HPV-infected laryngeal papillomas is rare (18). Studies have also reported low or zero prevalence of HPV in lung cancer (both squamous and adenocarcinoma) when compared to HNSCC $(19,20)$ in the same population. All this suggests a low likelihood of developing lung adenocarcinoma from an upper respiratory source of HPV infection or from HPV viraemia.

$H P V$ is epitheliotropic. Different studies in lung cancer have demonstrated wide-ranging differences of HPV among different world populations (Table II). It has been associated with squamous cell carcinoma and less so with adenocarcinoma 
(21-25). One of the earliest and largest series was reported from Okinawa where there was high prevalence of HPV among adenosquamous and squamous cell carcinoma of the lung (26). The authors subsequently updated their series and reported a reduction in squamous cell carcinoma in Okinawa and a corresponding reduction in HPV prevalence in the tumors screened (27). This reduction was attributed to reduction in HPV prevalence in the general population, and improvement in health and socioeconomic status that are known risk factors for HPV transmission. The single study that suggested rather higher HPV prevalence among nonsmokers and women in a Taiwanese population (28) is so far unique. In a subsequent study using similar methods the same group described lower prevalence in an ethnic Chinese population from Wuhan, China (29). There is the possibility that the use of nested-ISH could have led to over-amplification of HPV DNA. A recent Korean study using PCR methods for detecting HPV 16, 18 and 33 showed low prevalence of the high-risk genotypes averaging $10 \%$ and no association with smoking status or sex (30). A study from India that looked at 40 patients with lung cancer showed again low prevalence (5\%) of HPV 18 and absence of HPV 16 (31). Several recent well conducted studies from Europe using fresh frozen tissue and modern methodologies have similarly shown the absence or low prevalence of HPV DNA and associated E6/E7 mRNA in lung cancer tissues (32-34). The 'burden of proof' of a causal nature lies in the ability to demonstrate conclusively and repeatedly to a high degree the presence of HPV DNA in tumor tissue that is transcriptionally active, as is the case for HPV and cervical cancer. The consistently low or zero prevalence of HPV-DNA and HPV E6/E7 transcription in lung cancer argues that a global study may be required to determine the true role of HPV in lung cancer in different populations and ethnicities. A large worldwide study in the similar vein as those conducted by the International Association for Research into Cancer (IARC) for cervical carcinoma and HNSCC using uniform methodology for HPV detection may need to be done for this purpose.

EBV on the other hand is commonly prevalent in Asian populations and is intimately related to nasopharyngeal carcinoma (35). Epstein-Barr early RNA (EBER) in situ hybridization is a recognized standard for identifying the association of EBV with a tumor. EBER is expressed in all three forms of EBV latent infection and EBV-infected cells carry significant copy numbers of EBER making it a sensitive test (36). To date the described associations with lung cancer have been with the rare lymphoepithelioma subtype (37). A slightly higher frequency of EBER has been described in squamous cell carcinoma and neuroendocrine carcinomas (38). A subsequent study in small cell lung cancer however showed complete absence of EBER-1 by in situ hybridization (39) and no staining for ZEBRA and LMP-1 and only focal expression of EBNA-1. EBV was similarly absent in mesotheliomas and lung adenocarcinomas in the study by Conway et al (40). The absence of EBER-ISH in this large cohort of patients makes it unlikely that EBV is involved in the pathogenesis of lung adenocarcinoma among Asians.

In conclusion HPV and EBV vary in prevalence across different world populations. The absence of HPV or EBV in lung adenocarcinoma in this study parallels that seen in several other studies. It is unlikely that HPV or EBV is an important etiological agent in adenocarcinoma of the lung, even among the never-smokers.

\section{Acknowledgements}

This study was supported by National Medical Research Council Grants 0939/2005 and 0941/2005.

\section{References}

1. Hopkins JM and Evans HJ: Cigarette smoke-induced DNA damage and lung cancer risks. Nature 283: 388-390, 1980.

2. Lam B, Lam WK, Lam CL, Ooi GC, Ho JC, Wong MP and Tsang KW: Adenocarcinoma of the lung in Chinese patients: a revisit and some perspectives from the literature. Postgrad Med J 77: 708-712, 2001.

3. Seow A, Poh WT, Teh M, et al: Fumes from meat cooking and lung cancer risk in Chinese women. Cancer Epidemiol Biomarkers Prev 9: 1215-1221, 2000.

4. Li S, Pan D and Wang G: Analysis of polycyclic aromatic hydrocarbons in cooking oil fumes. Arch Environ Health 49: 119-122, 1994.

5. Zhao B, Seow A, Lee EJ, et al: Dietary isothiocyanates, glutathione S-transferase-M1, -T1 polymorphisms and lung cancer risk among Chinese women in Singapore. Cancer Epidemiol Biomarkers Prev 10: 1063-1067, 2001.

6. Ng DP, Tan KW, Zhao B and Seow A: CYP1A1 polymorphisms and risk of lung cancer in non-smoking Chinese women: influence of environmental tobacco smoke exposure and GSTM1/T1 genetic variation. Cancer Causes Control 16: 399-405, 2005.

7. Chen S, Xue K, Xu L, Ma G and Wu J: Polymorphisms of the CYP1A1 and GSTM1 genes in relation to individual susceptibility to lung carcinoma in Chinese population. Mutat Res 458: 41-47, 2001.

8. Syrjanen KJ: HPV infections and lung cancer. J Clin Pathol 55: 885-891, 2002.

9. Brousset P, Butet V, Chittal S, Selves J and Delsol G: Comparison of in situ hybridization using different nonisotopic probes for detection of Epstein-Barr virus in nasopharyngeal carcinoma and immunohistochemical correlation with anti-latent membrane protein antibody. Lab Invest 67: 457-464, 1992.

10. Bewtra C, Xie Q, Soundararajan S, Gatalica Z and Hatcher L: Genital human papillomavirus testing by in situ hybridization in liquid atypical cytologic materials and follow-up biopsies. Acta Cytol 49: 127-131, 2005.

11. Iftner T and Villa LL: Chapter 12: Human papillomavirus technologies. J Natl Cancer Inst Monogr 31: 80-88, 2003.

12. Bodaghi S, Wood LV, Roby G, Ryder C, Steinberg SM and Zheng ZM: Could human papillomaviruses be spread through blood? J Clin Microbiol 43: 5428-5434, 2005.

13. Sathish N, Abraham P, Peedicayil A, Sridharan G, John S, Shaji RV and Chandy G: HPV DNA in plasma of patients with cervical carcinoma. J Clin Virol 3: 204-209, 2004.

14. Chiou HL, Wu MF, Liaw YC, Cheng YW, Wong RH, Chen CY and Lee H: The presence of human papillomavirus type 16/18 DNA in blood circulation may act as a risk marker of lung cancer in Taiwan. Cancer 97: 1558-1563, 2003.

15. Chow VT, Tham KM, Lim-Tan SK, Sng IT and Bernard HU: Genital human papillomavirus infection among women from major ethnic groups in Singapore. Asia Oceania J Obstet Gynaecol 16: 373-377, 1990.

16. Clifford GM, Gallus S, Herrero R, et al: Worldwide distribution of human papillomavirus types in cytologically normal women in the International Agency for Research on Cancer HPV prevalence surveys: a pooled analysis. Lancet 366: 991-998, 2005.

17. Bao YP, Li N, Smith JS, Qiao YL, ACCPAB Members: Human papillomavirus type distribution in women from Asia: a metaanalysis. Int J Gynecol Cancer 18: 71-79, 2008.

18. Cook JR, Hill DA, Humphrey PA, Pfeifer JD and El-Mofty SK: Squamous cell carcinoma arising in recurrent respiratory papillomatosis with pulmonary involvement: emerging common pattern of clinical features and human papillomavirus serotype association. Mod Pathol 13: 914-918, 2000. 
19. Kaya H, Kotiloglu E, Inanli S, Ekicioglu G, Bozkurt SU, Tutkun A and Kullu S: Prevalence of human papillomavirus (HPV) DNA in larynx and lung carcinomas. Pathologica 93: 531-534, 2001.

20. Gorgoulis VG, Zacharatos P, Kotsinas A, et al: Human papilloma virus (HPV) is possibly involved in laryngeal but not in lung carcinogenesis. Hum Pathol 30: 274-283, 1999.

21. Szabo I, Sepp R, Nakamoto K, Maeda M, Sakamoto H and Uda H: Human papillomavirus not found in squamous and large cell lung carcinomas by polymerase chain reaction. Cancer 73: 2740-2744, 1994.

22. Aguayo F, Castillo A, Koriyama C, et al: Human papillomavirus-16 is integrated in lung carcinomas: a study in Chile. Br J Cancer 97: 85-91, 2007

23. Noutsou A, Koffa M, Egrazaki M, Siafakas NM and Spandidos DA: Detection of human papillomavirus (HPV) and $\mathrm{K}$-ras mutations in human lung carcinomas. Int J Oncol 8: 1089-1093, 1996.

24. Giuliani L, Jaxmar T, Casadio C, et al: Detection of oncogenic viruses (SV40, BKV, JCV, HCMV, HPV) and p53 codon 72 polymorphism in lung carcinoma. Lung Cancer 57: 273-281, 2007.

25. Kinoshita I, Dosaka-Akita H, Shindoh M, et al: Human papillomavirus type 18 DNA and E6-E7 mRNA are detected in squamous cell carcinoma and adenocarcinoma of the lung. Br J Cancer 71: 344-349, 1995

26. Tsuhako K, Nakazato I, Hirayasu T, Sunakawa H and Iwamasa T: Human papillomavirus DNA in adenosquamous carcinoma of the lung. J Clin Pathol 51: 741-749, 1998.

27. Iwamasa T, Miyagi J, Tsuhako K, Kinjo T, Kamada Y, Hirayasu T and Genka K: Prognostic implication of human papillomavirus infection in squamous cell carcinoma of the lung. Pathol Res Pract 196: 209-218, 2000.

28. Cheng YW, Chiou HL, Sheu GT, et al: The association of human papillomavirus 16/18 infection with lung cancer among nonsmoking Taiwanese women. Cancer Res 61: 2799-2803, 2001.

29. Fei Y, Yang J, Hsieh WC, et al: Different human papillomavirus 16/18 infection in Chinese non-small cell lung cancer patients living in Wuhan, China. Jpn J Clin Oncol 36: 274-279, 2006.
30. Park MS, Chang YS, Shin JH, et al: The prevalence of human papillomavirus infection in Korean non-small cell lung cancer patients. Yonsei Med J 48: 69-77, 2007.

31. Jain N, Singh V, Hedau S, et al: Infection of human papillomavirus type 18 and p53 codon 72 polymorphism in lung cancer patients from India. Chest 128: 3999-4007, 2005.

32. Brouchet L, Valmary S, Dahan M, Didier A, Galateau-Salle F, Brousset P and Degano B: Detection of oncogenic virus genomes and gene products in lung carcinoma. Br J Cancer 92: 743-746, 2005.

33. Coissard CJ, Besson G, Polette MC, Monteau M, Birembaut PL and Clavel CE: Prevalence of human papillomaviruses in lung carcinomas: a study of 218 cases. Mod Pathol 18: 1606-1609, 2005.

34. Clavel CE, Nawrocki B, Bosseaux B, et al: Detection of human papillomavirus DNA in bronchopulmonary carcinomas by hybrid capture II: a study of 185 tumors. Cancer 88: 1347-1352, 2000.

35. Henderson BE, Louie EW, Jing JS and Alena B: Epstein-Barr virus and nasopharyngeal carcinoma: is there an etiologic relationship? J Natl Cancer Inst 59: 1393-1395, 1977.

36. Ambinder RF and Mann RB: Detection and characterization of Epstein-Barr virus in clinical specimens. Am J Pathol 145: 239-252, 1994.

37. Han AJ, Xiong M and Zong YS: Association of Epstein-Barr virus with lymphoepithelioma-like carcinoma of the lung in southern China. Am J Clin Pathol 114: 220-226, 2000.

38. Grinstein S, Preciado MV, Gattuso P, Chabay PA, Warren WH, De Matteo E and Gould VE: Demonstration of Epstein-Barr virus in carcinomas of various sites. Cancer Res 62: 4876-4878, 2002.

39. Chu PG, Cerilli L, Chen YY, Mills SE and Weiss LM: EpsteinBarr virus plays no role in the tumorigenesis of small-cell carcinoma of the lung. Mod Pathol 17: 158-164, 2004

40. Conway EJ, Hudnall SD, Lazarides A, Bahler A, Fraire AE and Cagle PT: Absence of evidence for an etiologic role for EpsteinBarr virus in neoplasms of the lung and pleura. Mod Pathol 9: 491-495, 1996. 